\title{
1 Assessment of Exposure for Pesticide Handlers in Agricultural, Residential and Institutional Environments
}

\author{
RICHARD A. FENSKE ${ }^{\mathbf{1}}$ and EDGAR W. DAY, JR ${ }^{\mathbf{2}}$ \\ ${ }^{1}$ Pacific Northwest Agricultural Safety and Health Center, University of \\ Washington, Seattle, WA, USA \\ ${ }^{2}$ E. W. Day Consulting, Indianapolis, IN, USA
}

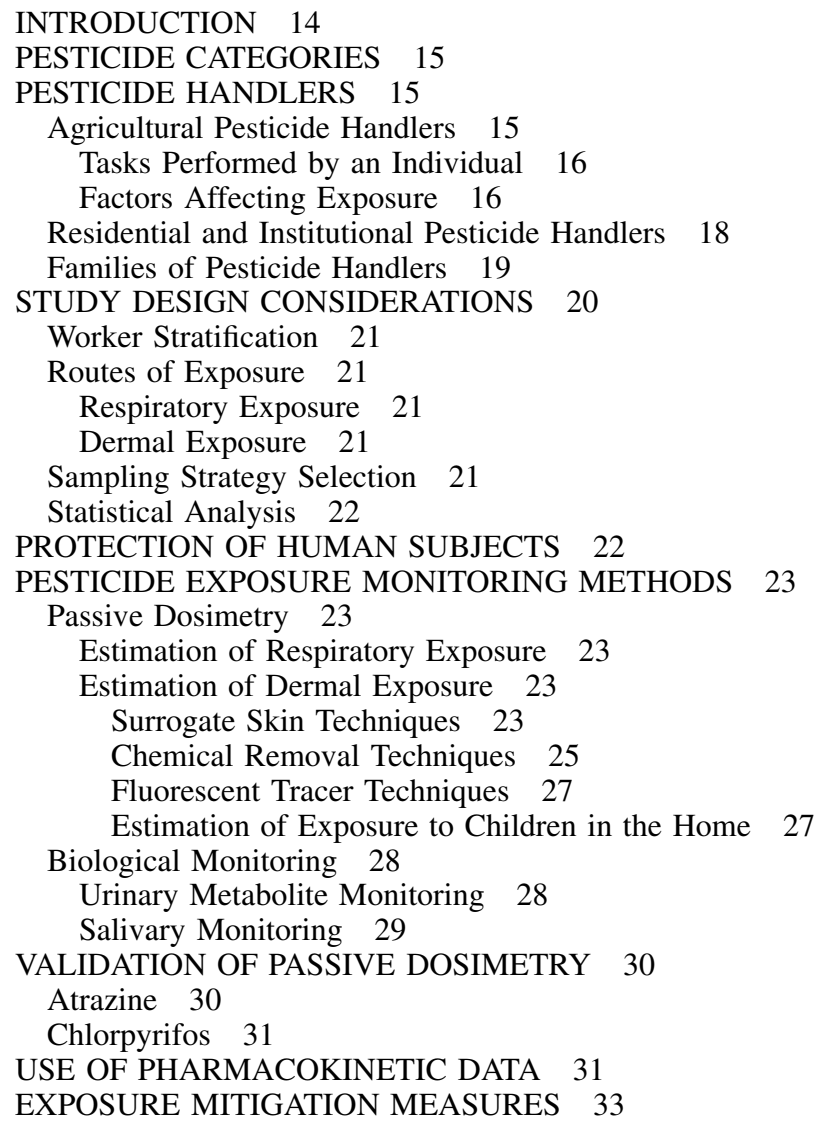




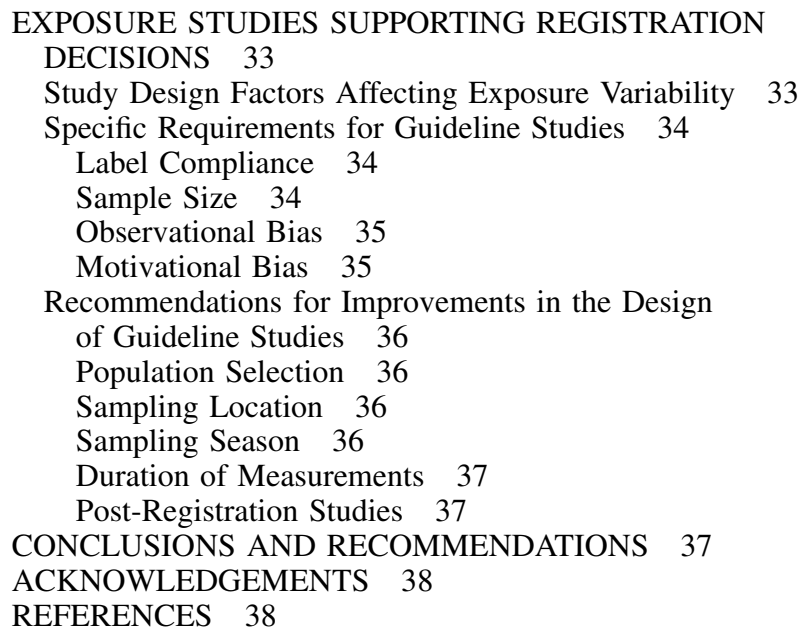

\section{INTRODUCTION}

Occupational pesticide exposure holds a peculiar status within the field of occupational health and safety, both from a scientific and regulatory perspective. Methods for personal monitoring of dermal exposure first arose in the context of pesticide applications in agriculture, pioneered by scientists in the USA Public Health Service (Batchelor and Walker, 1954; Durham and Wolfe, 1962). These methods gained worldwide recognition in the early 1960s, and remain a component of exposure assessment practice today. This work pre-dated most personal monitoring methods that were developed for industrial workplaces.

Nonetheless, occupational hygiene - the science of workplace hazard recognition, evaluation and control - has turned its attention only belatedly to exposures in the agricultural workplace. The majority of scientists who investigated pesticide exposures through the 1980s came from disciplines allied more with the agricultural sciences than with the health sciences. Thus, for many years, standard occupational hygiene procedures were not applied to these populations.

In the past decade, however, the occupational health and safety community has directed greater attention to pesticide exposures among workers and their families. Initiatives, focused on minority workers, women and the children of workers, have also made pesticide exposure assessment a timely topic for scientific investigation and medical management. Finally, major new epidemiologic initiatives in both the United States and Canada have given new stimuli to the study of occupational pesticide exposure in farming (Alavanja et al., 1996; Arbuckle et al., 1999).

The purpose of this present chapter is to critically discuss study methodologies used to derive quantitative estimates of exposure associated with the mixing, loading and application of pesticides for agricultural, residential and institutional 
scenarios. The exposure assessment methodologies presented here are also relevant to the assessment of post-application risks to workers, which is addressed in more detail in Chapter 2. This review will also comment on the exposure of children of pesticide workers, as they appear to be a sub-population at potentially high risk for exposures. This chapter will review basic characteristics of pesticide products and populations at risk, and will then focus on study design considerations, and methods for monitoring and assessment. A final section will discuss the differences between guideline studies conducted in support of regulation and operational studies and will make recommendations on ways to improve exposure studies.

\section{PESTICIDE CATEGORIES}

Pesticides are a heterogeneous group of chemicals developed to control a variety of pests. The term can be applied to microorganisms with biocidal properties, as well as to common household products. Pesticides are generally categorized according to the type of pest for which they have been shown to be efficacious. The primary categories are insecticides, herbicides and fungicides. Many other categories, such as wood preservatives, termiticides, rodenticides, algaecides, repellents and miticides, are also in use. An excellent resource book describing the various pesticide classes is available (Ware, 1994).

Pesticides are manufactured and sold in various formulations. The latter are composed of the technical active ingredient (also referred to as the active substance) and other chemicals, including water (formulants) which are designed to improve effectiveness, or may enhance storage or safety of the active ingredient. Persistence of the pesticide in the environment can also be affected by formulation. Types of formulation may be liquid or powder sprays (e.g. emulsifiable concentrates and wettable powders), dusts, aerosols or granular materials. The formulation may be designed to volatilize quickly, or to act in a slow-release or controlled-release manner. Knowledge of the formulation type can often prove useful in understanding the potential for worker exposures.

\section{PESTICIDE HANDLERS}

\section{AGRICULTURAL PESTICIDE HANDLERS}

Workers who mix, load and apply formulated pesticides may be classified into a single category of pesticide handlers. Such handlers are normally considered to be the group that will receive the greatest exposure because of the nature of their work, and are therefore at highest risk for acute intoxications. The potential for development of long-term adverse health effects depends on such factors as frequency of application (times per season) and exposure duration (years of application). This worker population has been the subject of significant regulatory scrutiny, and exposure databases have been developed in both North America 
and Europe to better understand the extent and variability of exposure. A comprehensive review of these databases has been published (van Hemmen, 1992), and is the subject of Chapter 5 in this book. A publication from an international workshop also provides an excellent review of these issues (Curry et al., 1995).

Exposure is also dependent on the type of task performed, and therefore it is important to collect data for each.

\section{Tasks Performed by an Individual}

- Mixing/loading - this work activity involves weighing or measuring the product in some fashion, mixing the measured concentrated product with a diluent, usually water, either inside or outside of the application equipment, loading the product (either neat or partially diluted) into the equipment either manually or via a pumping or other system, adding additional diluent if required, and mixing it in the application equipment. For some products, such as dust formulations, no diluent is used.

- Application - this task involves driving a vehicle which either pulls the application equipment or where the equipment is contained within the vehicle itself. This would include trucks (with tank and mounted spray rig), tractors (which pull a tank and spray rig), other self-contained units and aircraft (helicopters or fixed-wing planes), which are equipped with tanks or hoppers and spray, dusting or granular application equipment.

- Mixing/loading/application - this work activity involves all of the tasks involved in the application of the pesticide. This is the most common activity for farmers who apply their own pesticides. Commercial, for hire, applicators typically have separate tasks. There are also workers in greenhouse operations and residential settings where the typical equipment may be backpack sprayers, hand-held tank sprayers, push-type applicators and belly-grinders.

- Flagging - this activity occurs when pesticides are applied aerially. The workers position themselves, with a flag, at the edge of fields to be treated aerially to assist the pilot in identifying his line of flight in order to obtain complete coverage of the target area without significant overlap. Such workers may receive direct contact with the pesticide product or spray during the course of the application.

- Other activities - certain large application equipment may become heavily contaminated during the application operation and require 'clean-up'. Some application procedures may require an immediate second operation, such as soil incorporation of an herbicide immediately after application, or irrigation of a pesticide into a lawn soon after treatment. It may be appropriate in some circumstances to monitor exposure during such activities.

\section{Factors Affecting Exposure}

Exposure during specific pesticide handling events can be modified by several important factors, as follows: 
- Type of equipment used - mixing and loading of pesticides can result in substantial exposures over brief periods; closed systems have been developed to mitigate such exposures, and when properly used and maintained, have proven effective. Applications with such equipment as air-blast (speed) sprayers produce much higher exposures than applications with ground-boom equipment, although most of the exposure occurs from mixing/loading the concentrate. Newer spray rigs are typically equipped with enclosed cabs which have ventilation systems that provide substantial protection against dermal exposure. They also reduce inhalation exposure to a level comparable to a National Institute of Occupational Safety and Health (NIOSH)-approved dust/mist or organicvapour removing respirator. Performance criteria for closed cabs are published in the United States Environmental Protection Agency (USEPA) Worker Protection Standard (WPS 40CFR, part 170.240 (d) (5)) (USEPA, 1992).

- Formulation - different formulation types can produce very different exposure patterns. Liquids, such as emulsifiable concentrate (EC) solutions, and aqueous suspensions (ASs) are prone to splashing and occasionally spillage, resulting in permeation of clothing and skin contact. Emergency washing facilities are often required in proximity to mixing stations in order to prevent overexposures. Solids, such as wettable powders (WPs), granules and dusts, may present a plume of dust while being loaded into application equipment, so producing both a respiratory hazard and exposures to the face and eyes. Some of the newer water-dispersible granules (WDGs) have been formulated to drastically reduce this potential exposure to dust particles.

- Packaging - the type and size of packaging can also influence potential exposure. The opening of bags, depending on type, can result in significant exposure. The size of cans, bottles or other liquid containers may affect the potential for spillage and splashing. Many larger-volume pesticides are delivered in larger bulk and 'minibulk' containers, which when used in combination with the closed mixing/loading systems described above, significantly reduce handler exposure.

- Environmental conditions - climatological factors, such as temperature and humidity, may influence chemical volatility, perspiration rate and use of protective clothing. Wind can have a profound effect on spray drift, and resultant exposure to the applicator.

- Protective clothing and personal protective equipment - protective clothing, such as chemical-resistant gloves and coveralls, are often required during pesticide handling and application. Label requirements may also call for respiratory protection. Use of such personal protective equipment can dramatically reduce skin contact and inhalation exposures.

- Hygienic behaviour - worker care in regard to pesticide handling can also have substantial impact on exposure. Workers who avoid mixing and spraying during windy conditions can reduce their exposure. Proper use and maintenance of protective clothing are also important behaviours associated with reduced chemical exposures. 
- Dual activities - in exposure studies for agricultural scenarios, mixing/loading tasks are often monitored separately from the application, even though the same individual may frequently perform both tasks, particularly in smaller farm operations. It has been observed that mixer-loaders typically have the highest exposure, mainly to their forehead, forearms and hands, for many scenarios, regardless of the type of application. This has been attributed to the fact that they are handling the concentrated pesticide. The advantage to conducting studies in this way is to permit identification of the principal sources of contamination, and to provide more detailed recommendations for personal protective equipment or other mitigation measures. For workers who conduct both tasks, the exposures from mixing-loading and from application are summed.

- Duration of activity - in addition to measuring the unit exposure for a worker on a daily basis for a particular scenario, exposure and risk assessment requires knowledge and characterization of the frequency and duration of exposure, both on a seasonal and lifetime basis. For example, an individual farmer may apply a pesticide once a year, while a commercial applicator may apply a pesticide for many consecutive days or weeks in a season. Since the exposure associated with mixing-loading is greater than for other activities, it is important to normalize the data with respect to the number of tank fills or kilograms of active ingredient handled.

Table 1.1 illustrates the influence of some of the above noted variables on unit exposure $(\mu \mathrm{g} / \mathrm{kg}$ of active ingredient handled) for selected scenarios.

\section{RESIDENTIAL AND INSTITUTIONAL PESTICIDE HANDLERS}

Workers who mix, load and apply pesticides commercially in residential and institutional settings are often referred to as pest control operators (PCOs). Their potential for exposure is distinguished from agricultural pesticide handlers in a number of important ways. First, PCOs may handle pesticides every day, and may use the same compound with high frequency. Secondly, many of these workers have limited training ${ }_{2}$ although many countries require workers who 'spray for hire' to be licensed. While they may be required to work under the supervision of a licensed pesticide applicator, they often have no supervisor on site during applications. Thirdly, this population has a relatively high turnover rate, and so exposure duration (years of exposure) may be limited. Finally, the volume of chemicals used for most residential and institutional applications is small when compared to agricultural applications.

Exposure studies of adults who handle pesticides in and around their homes would normally require the same methodologies used for agricultural and commercial applicators. Products that contain only a small proportion of active ingredient (typically $0.5-1.0 \mathrm{wt} \%$ ) are sold directly to the public for lawn and garden use. Consumers who use these pesticide products generally have no formal training in mixing and application techniques, but are provided label instructions for proper handling. 
Table 1.1 Effect of various factors on pesticide exposure. All data are unit exposure values $(\mu \mathrm{g} / \mathrm{kg}$ of active ingredient (a.i.) handled), taken from PHED (1992). Values are central tendency measures based on high confidence data sets

\begin{tabular}{|c|c|c|}
\hline \multirow{2}{*}{$\frac{\text { Factor }^{a}}{{\text { Formulation type }(\mathrm{M} / \mathrm{L})^{b}}^{b}}$} & \multicolumn{2}{|c|}{ Exposure $(\mu \mathrm{g} / \mathrm{kg} \text { a.i. })^{a}$} \\
\hline & $\begin{array}{l}\text { Dry flowable } \\
\text { Granular } \\
\text { Liquid }\end{array}$ & $\begin{array}{r}163.7 \\
13.0 \\
51.1\end{array}$ \\
\hline Protective clothing for $\mathrm{M} / \mathrm{L}^{c}$ & $\begin{array}{l}\text { Gloves } \\
\text { No gloves }\end{array}$ & $\begin{array}{r}51.1 \\
6300.0\end{array}$ \\
\hline $\begin{array}{l}\text { Engineering controls } \\
\text { For ground-boom applicator }{ }^{d}\end{array}$ & $\begin{array}{l}\text { Closed cab } \\
\text { Open cab }\end{array}$ & $\begin{array}{l}11.0 \\
33.0\end{array}$ \\
\hline $\begin{array}{l}\text { Engineering controls for } \\
\text { air-blast applicator }\end{array}$ & $\begin{array}{l}\text { Closed cab (air blast) } \\
\text { Open cab (air blast) }\end{array}$ & $\begin{array}{r}42.0 \\
561.7\end{array}$ \\
\hline $\begin{array}{l}\text { Engineering controls for } \mathrm{M} / \mathrm{L} \\
\quad \text { (liquids) }{ }^{f}\end{array}$ & $\begin{array}{l}\text { Open } \mathrm{M} / \mathrm{L} \\
\text { Closed } \mathrm{M} / \mathrm{L}\end{array}$ & $\begin{array}{l}51.0 \\
19.0\end{array}$ \\
\hline Application method ${ }^{g}$ & $\begin{array}{l}\text { Ground boom (open cab) } \\
\text { Air blast (open cab) } \\
\text { Aerial (fixed-wing and rotary) }\end{array}$ & $\begin{array}{r}33.0 \\
828.2 \\
9.7\end{array}$ \\
\hline $\begin{array}{l}{ }^{a} \mathrm{M} / \mathrm{L} \text {, mixer-loader. } \\
{ }^{b} \mathrm{M} / \mathrm{L} \text { (open system) wearing single lay } \\
{ }^{c} \mathrm{M} / \mathrm{L} \text { (open liquid system) wearing sin } \\
{ }^{d} \mathrm{Ground}-b o o m \text { applicator wearing sing } \\
{ }^{e} \text { Air-blast applicator wearing single lay } \\
{ }^{f} \mathrm{M} / \mathrm{L} \text { (liquids) wearing single layer of }\end{array}$ & $\begin{array}{l}\text { plus gloves. } \\
\text { lothing (with and without gloves). } \\
\text { thing and gloves. } \\
\text { and gloves. } \\
\text { gloves. }\end{array}$ & \\
\hline
\end{tabular}

\section{FAMILIES OF PESTICIDE HANDLERS}

Increased attention has been directed at spouses and children of agricultural workers. The US National Institute for Occupational Safety and Health (NIOSH) has prepared a review of children's exposures to environmental health hazards, including pesticides associated with parental occupation (NIOSH, 1995).

The exposure metrics in studies of effects in children exposed as a result of their parent's occupational exposure to pesticides are frequently based on pesticide use records or on questionnaire data, rather than on actual measurements of pesticide exposure in children (Kristensen et al., 1996; Garry et al., 1996).

The exposure potential for children of agricultural families may be higher than for other child populations, since concentrated formulations of pesticides are stored and/or mixed, although not used in high concentration near the home. Another source of exposure may result from the inadvertent introduction into the home via various 'take-home' pathways. Several studies have also shown that agricultural workers bring contaminated clothing into the home (Chiao-Cheng et al., 1989; Clifford and Nies, 1989). Poor hygienic practices such as these 
among pesticide formulators have been associated with measurable blood levels of pesticides (chlordecone or kepone) in family members (Cannon et al., 1978). Classic organophosphorous (OP) pesticide exposure symptoms in spouses and children of greenhouse workers have been reported (Richter et al., 1992).

A study in Washington State found that children living with agricultural workers and in proximity to tree fruit orchards may have more opportunity for exposure than children living in homes without such risk factors (Simcox et al., 1995). These findings were supported by an additional study which measured pesticide metabolites in children's urine (Loewenherz et al., 1997; Lu et al., 2000).

Current attempts to control such exposures are therefore aimed at reducing 'track-in' of pesticides from the outdoors, proper handling and cleaning of work clothing, and possible restrictions on children's activities during or following pesticide applications. In addition, agricultural workers should be cautioned regarding the dangers inherent in the use of acutely toxic pesticides in residential environments.

\section{STUDY DESIGN CONSIDERATIONS}

Exposure assessments may be conducted for one of four purposes: hazard evaluation leading to appropriate control efforts, monitoring to ensure compliance with workplace standards, dose-response characterization within the context of epidemiological studies, and estimation of dose or uptake for risk assessments. Assessment strategies and measurement techniques will differ depending on the purpose at hand.

Most studies of pesticide handler exposure have been conducted to obtain an estimate of their exposure when the pesticide is applied according to label directions. This exposure estimate is then used in the risk assessment conducted by regulatory agencies to determine whether the pesticide should be registered. The various safety (uncertainty) factors that are applied in the risk assessment compensate for the fact that some workers may not adhere to the label directions. A second type of study that would be useful is one in which the exposure to workers who are not adhering to the directions on the label would be measured. The impact that this has on the amount of exposure will be discussed later. Current risk assessment procedures require knowledge of the population at risk and the distribution of exposures within this population, as well as information on the toxicity of the compound under evaluation (NAS, 1983). The primary goal of conducting an exposure assessment in support of a registration request is to identify a study population which is representative of the population at risk, and to then conduct a sampling program that characterizes well the central tendency and variability of the exposures which these individuals receive.

In support of this goal, four fundamental study design concerns should be considered. 


\section{WORKER STRATIFICATION}

Occupational hygienists have traditionally evaluated exposures according to job title or work activity within industrial settings (Corn and Esmen, 1979). Grouping workers in these ways tends to increase the precision of estimated mean exposures. One example of a worker grouping is the homogeneous exposure group, which has been proposed as a basis for reducing sampling burden for making compliance decisions (Hawkins et al., 1991). Assignment of workers to such groups can presumably be done a priori through knowledge of environmental conditions and time-activity patterns, although a subsequent analysis demonstrated that such classifications are not necessarily accurate (Kromhout et al., 1993).

In the case of agricultural worker exposure, researchers have traditionally sub-divided worker populations into such categories as pesticide mixer/loaders, applicators, flaggers and fieldworkers, recognizing that exposure processes are markedly different for these groups. The categorization of workers by van Hemmen (1992), according to work activity, environment and application techniques, represents the most thorough analysis to date of exposure variability within and across mixer/loader and applicator groups.

\section{ROUTES OF EXPOSURE}

\section{Respiratory Exposure}

Respiratory exposure assessments place great emphasis on the accurate measurement of environmental concentrations in the air breathed by the worker, and normally make simplifying assumptions regarding contact rate (standard respiratory volume) and absorption (100\% absorption).

\section{Dermal Exposure}

It is clear that the behavioural component of exposure is very important, and that uptake of chemicals through the skin can exhibit high variability. Since the primary route of exposure in pesticide handlers is through the skin, most work in this field has focused on characterizing deposition of chemicals on the skin and their subsequent absorption into the body. In the absence of actual data on dermal absorption, regulatory agencies may use default values ranging from 1 to $100 \%$, depending on the chemical characteristics and on the policy of their agency.

\section{SAMPLING STRATEGY SELECTION}

The fundamental issues in field study design can be outlined by a series of simple interrogatives: who, where, when, how long, how often and how many? The answers to these questions require substantial prior knowledge of worker populations and working conditions, as well as the toxicological and metabolic 
characteristics of the pesticide. An optimal field study protocol would be constructed of an idealized study design, tempered by the practical difficulties inherent in human population studies, as well as financial limitations.

\section{STATISTICAL ANALYSIS}

The role of statistical principles in study design has been the subject of extensive discussion within the occupational hygiene community (Nicas et al., 1991; Teschke et al., 1994). Extensive analysis of air sampling data has led to the generalization that occupational exposures are log-normally distributed, both within and between workers (Rappaport, 1991). Analysis of data sets generated by the North American Pesticide Handlers Exposure Database (PHED) indicates similar distribution patterns (PHED, 1992). Most researchers in this field have concluded that the arithmetic mean exposure is the most appropriate statistic to summarize the central tendency of these types of exposure distributions for individual workers (within-worker), because of its direct relationship to cumulative dose under chronic low-level exposure conditions (Rappaport, 1991). However, the geometric mean exposure of a stratum of workers (between-worker) is the most logical basis from which to calculate exposure percentiles within the group (e.g. 95th, 90th and 50th percentiles). The variance in exposure for both individual workers and groups of workers is best described by the geometric standard deviation. Hawkins et al. (1992) have indicated that 6-11 samples may be sufficient to estimate mean exposures, but that larger sample sizes ( 20 or more) are needed to reliably estimate the variance. Buringh and Lanting (1991) have conducted modeling exercises of exposure, and have also concluded that exposure variance will likely be underestimated if too few samples are taken. In situations where only a few samples can be taken, a conservative (high) estimate of the variance can be employed. The application of statistical principles to study design is an important issue deserving of greater attention within the pesticide exposure assessment community.

\section{PROTECTION OF HUMAN SUBJECTS}

A number of governments have established common requirements for the protection of human subjects involved in research studies. These have been codified in the United States through the Code of Federal Regulations (40 CFR 26). In addition to this 'common rule', Section 12(a)(2)(P) of the Federal Insecticide, Fungicide and Rodenticide Act (FIFRA) provides that it shall be unlawful for any person to use any pesticide in tests on human beings unless they: (1) are fully informed about the nature of the tests and the potential health consequences, and (2) freely volunteer to participate.

In 1992, the USEPA published its Worker Protection Standard (WPS) Final Rule (USEPA, 1992). This WPS contains provisions intended to inform agricultural employees about the hazards of pesticides, and provides specific protective clothing requirements for pesticide handlers. In conducting any field study, the 
investigator must ensure that the applicable provisions of the WPS regulations are being fulfilled. Generally, hazard information must be available for all workers, appropriate protective clothing must be provided, and decontamination sites and emergency assistance must be available. Volunteers for studies must receive adequate training prior to the conduct of the study, and should sign an informed consent document that delineates the potential hazards involved in the study.

\section{PESTICIDE EXPOSURE MONITORING METHODS}

The two primary methods for assessing exposure to pesticides are passive dosimetry, which is more commonly used, and biological monitoring.

Passive dosimetry measures the amount of pesticide that comes into contact with the skin, clothing and the breathing zone of the worker. From the late 1960s until the 1980s, large numbers of worker exposure studies were conducted using passive dosimetry methods which measured the amount of pesticide that came into contact with the skin of the worker and was measured on patches attached to the clothing or from extracts of the clothing. The amount of pesticide that was absorbed into the body was not measured. These studies were reviewed by Wolfe (1976) and Davis (1980). More recent, detailed discussions of these methods are presented in OECD (1997) and USEPA (1998).

\section{PASSIVE DOSIMETRY}

\section{Estimation of Respiratory Exposure}

Air sampling for occupational exposure to pesticides normally consists of measurement of pesticide concentrations in the worker's breathing zone, with a portable air-sampling pump and a sampling train which includes some type of collection device. The latter device, or sampling media, selected are based on the physical and chemical properties of the compound to be measured. Field workers may be exposed to chemical vapors, solid particulates or waterbased aerosols. Examples of sampling media include membrane filters, sorbent tubes, polyurethane foam and charcoal. A discussion of pesticide exposure provides a useful review of methods for respiratory exposure measurement (Nigg et al., 1990).

\section{Estimation of Dermal Exposure}

Dermal exposure sampling methods fall into three general categories: surrogate skin techniques, chemical removal techniques and fluorescent tracer techniques (Fenske, 1993a).

\section{Surrogate Skin Techniques}

(1) Patches. Surrogate skin methods involve placing a collection medium against the skin and subsequently analyzing it for chemical content. The most common 
approach has come to be known as the patch technique. The latter was developed by US Public Health researchers in Wenatchee, Washington in response to potential acute intoxications among pesticides handlers (Durham and Wolfe, 1962). The technique has since become accepted as a standard internationally (WHO, 1986; USEPA, 1987). In most cases, ten patches are attached to clothing or directly to the skin on the following body regions: chest (1); back (1); upper arms (2); forearms (2); thighs (2); lower legs (2). Chemical loading on the patch (mass per unit area) is then extrapolated to the skin surface area of the appropriate anatomical region (Table 1.2).

The utility of the patch technique for quantitative exposure estimation presupposes that exposure is uniform across each body region; however, under some circumstances, this assumption is probably not valid (Franklin et al., 1981; Fenske, 1990). Despite such limitations, patch sampling can serve as a simple and cost-effective method for hazard evaluation and control through comparative studies. For example, a recent study of pesticide applicators in Brazil used patches to demonstrate a significant reduction in exposure due to changes in application equipment (Machado et al., 1992). Studies in greenhouses have also used patches to characterize the effects of ventilation (Methner and Fenske, 1994a). Numerous investigators have quantified protective clothing penetration by placing patch samplers inside and outside of the fabric barrier (Gold et al., 1982; Nigg et al., 1986; Keeble et al., 1988; Fenske et al., 1990; Nigg et al., 1992).

The composition and size of the patches used in dermal exposure studies are important considerations and should be based on the characteristics of the pesticide and the exposure scenario. For sprays, the use of papermaking pulp or

Table 1.2 Surface areas for regions of the adult body and locations of dermal exposure pads that represent these regions (USEPA, 1987)

\begin{tabular}{lcl}
\hline Body region & $\begin{array}{c}\text { Surface area of } \\
\text { region }\left(\mathrm{cm}^{2}\right)\end{array}$ & \multicolumn{1}{c}{ Patch location } \\
\hline Head & $1300^{a}$ & Shoulder, back, chest, head \\
Face & 650 & Upper chest, head \\
Back of neck & 110 & Upper back \\
Front of neck + 'V' of chest & 150 & Upper chest, head \\
Chest/stomach & 3550 & Chest \\
Back & 3550 & Back \\
Upper arms & 2910 & Shoulders, upper arms \\
Forearms & 1210 & Forearms \\
Hands & 820 & Gloves or hand rinse \\
Thighs & 3820 & Thighs \\
Lower legs & 2380 & Shins \\
Feet & 1310 & Use socks \\
\hline
\end{tabular}

${ }^{a}$ Surface area for the head includes the $650 \mathrm{~cm}^{2}$ face surface area.

${ }^{b}$ Exposure to the head may be estimated by using the mean of the shoulder, back and chest patches, or by using a head patch attached to the worker's cap. 
alpha-cellulose is recommended, because high-quality alpha-cellulose will absorb a considerable amount of material without disintegrating. Preparative chromatography paper is also satisfactory for this purpose. Other appropriate materials include surgical gauze, clothing material and blotter paper. Patches constructed from surgical gauze are suggested for dry formulations such as dusts or granules.

(2) Body garments. Whole-body garments have been proposed as a standard method for measuring pesticide exposures for registration purposes (Chester et al., 1992; Teschke et al., 1994). Whole-body garments generally consist of long underwear garments or coveralls worn next to the skin with no protective layer. Thus, there is potential for penetration of residues through the garments to the skin and a resultant underestimate of exposure. 'Tyvek' coveralls have the advantage of being impermeable and therefore do not underestimate exposure to the skin. The garments typically represent the torso and limbs, but not the head, face, neck, hands and feet. Thus, the principle advantage of this method when compared to the patch technique is that no extrapolation to total surface area is required for the torso.

Body garments, such as gloves, can also be used to sample specific anatomical regions (Davis et al., 1983; Fenske et al., 1989; Brouwer et al., 1992). Some investigators have concluded that garment samplers such as gloves are likely to overestimate exposures (Davis et al., 1983), but others have found that glove measurements did not differ significantly from handwash measurements over an extended sampling period (Fenske et al., 1989).

No standard materials have been developed for whole-body garment sampling. Studies to date have used absorbent fabric such as cotton or cotton/polyester. Inner garments might consist of white cotton socks (feet), T-shirts (upper torso), briefs (lower torso) and thermal underwear bottoms and tops (the whole body, except hands, feet and head).

A key assumption of all of these techniques is that the patch or garment captures and retains chemicals in a manner similar to that of skin. This assumption, however, has not been validated systematically. Ideally, patches and garments, employed as dermal samplers, would be pre-tested for their ability to absorb and retain the particular chemical under study.

\section{Chemical Removal Techniques}

Washing or wiping the skin can remove chemical deposits, and chemical concentrations can be measured (Durham and Wolfe, 1962; Davis, 1980). Wash techniques are generally used only to assess hand exposure, while wiping techniques can, in theory, be applied to other skin surfaces.

(1) Washes. Several types of solutions or liquids can be used to collect handwash samples, including various types of aqueous surfactant solutions, and neat isopropanol or ethanol. The physico-chemical properties of the pesticide should guide selection of the rinse solvent, especially the octanol-water partition coefficient 
$\left(K_{\text {ow }}\right)$. The aqueous solutions may be preferred for the more water-soluble pesticides, whereas the organic solvents may provide better results for highly waterinsoluble chemicals. The water used for preparing aqueous solutions should be either distilled or deionized if possible. Several commercially available surfactants have been used to prepare hand-rinse solutions ('Sur-Ten', 'Aerosol OT-75', 'Emcol 4500' and 'Nekal WT-27') at concentrations of about $0.01 \%$.

A wide array of procedures has been used to obtain hand-rinse samples, raising the likelihood that results across studies are probably not comparable. In some cases, test subjects place their hands in a large bowl $(2-3 \mathrm{~L})$ containing the rinse solutions, and rub their hands together in a washing motion. In other studies, the liquid is simply poured slowly over the hands, while the test subjects wring their hands in a washing motion, and the solution is collected in a wide-top container. The standard method described by Durham and Wolfe (1962) and Davis (1980) involves the hand placed in a plastic bag with solvent, and shaken for $30 \mathrm{~s}$; the procedure is repeated with a new bag and solvent, and for each hand. The four bags are then pooled to provide a single handwash sample. This method has demonstrated good reproducibility in laboratory studies (Fenske and Lu, 1994). Handwash sampling should be conducted when workers routinely clean their hands, at scheduled breaks (lunch time), and at the end of the work shift. It is also recommended that a wash be conducted just prior to the initiation of the exposure monitoring to remove any pre-existing residues. The major drawback of handwash methods is that they do not necessarily remove the total amount of chemical deposited on the skin. It is remarkable that virtually no validation studies have been conducted for this technique during its nearly 40 years of use in the field. One study of chlorpyrifos skin exposure found that washing one minute after skin contact removed less than $50 \%$ of the amount applied, and that washing one hour after contact removed less than $25 \%$ (Fenske and Lu, 1994).

Removal efficiency was also observed to decrease with decreased skin loadings. These results indicate that data based on such methods may be highly variable, and will require appropriate removal efficiency studies as a part of method validation and quality assurance.

(2) Wipes. Skin-wipe methods have also been developed to assess pesticide applicator exposure to the hands, face and neck, but have not yet been validated. One laboratory study has reported that pesticides can be removed from the hands by wiping with relatively high efficiency (Geno et al., 1996). However, the wiping was conducted immediately following exposure, and neither the effect of skin residence time, nor the effect of concentration on removal efficiency, was determined. A recent field study of agricultural re-entry workers found that hand-wiping produced 6-fold lower exposure estimates than did hand washing under similar exposure conditions (Fenske et al., 1999). Skin wiping appears to be a relatively simple and convenient technique, but in light of these conflicting findings, it does not yet appear to be acceptable as a quantitative exposure assessment method. 


\section{Fluorescent Tracer Techniques}

Visualization of skin exposure patterns with fluorescent tracers is a relatively new assessment method. Compounds known as fluorescent whitening agents (FWAs) were first demonstrated to be useful tools for characterizing skin deposition of pesticide sprays in the 1980s (Franklin et al., 1981; Fenske et al., 1985, 1986). Qualitative studies with tracers can provide important information about skin deposition patterns, protective clothing performance and work practices (Fenske, 1988). Exposure evaluations require introduction of the fluorescent tracer into the production system, and subsequent evaluation of workers in a dark area using long-wavelength ultraviolet illumination. The tracer compounds are not visible under normal lighting conditions, and so the patterns of exposure which workers view on their skin can come as quite a surprise.

The use of fluorescent compounds can be coupled with video-imaging analysis to produce exposure estimates over virtually the entire body (Fenske and Birnbaum, 1997). This approach requires pre- and post-exposure images of skin surfaces under long-wavelength ultraviolet illumination, development of a standard curve relating dermal fluorescence to skin-deposited tracer, and chemical residue sampling to quantify the relationship between the tracer and the chemical substance of interest as they are deposited on the skin.

This method was used to evaluate performance of chemical protective clothing during air-blast applications of ethion in citrus orchards (Fenske, 1993b) and demonstrated limitations in garment design. The method has also been used to examine pesticide exposure during greenhouse applications (Methner and Fenske, 1994a, 1994b). Several laboratories have adopted this method, or have developed similar approaches (Roff, 1994; Archibald et al., 1995; Bierman et al., 1998; Kross et al., 1996).

Fluorescent tracer techniques hold the promise of improved accuracy in assessing dermal exposures, as they require no assumptions regarding the distribution of exposure across skin surfaces. However, this approach also has several limitations. First, it requires introduction of the tracer compound into the agricultural spray mix. Secondly, there must be demonstration of a correspondence between pesticide deposition and deposition of the fluorescent compound for the production, such that the fluorescence can indeed be considered a 'tracer' of chemical deposition. Thirdly, range-finding and quality assurance studies may be needed to ensure the accuracy of tracer measurements. Fourthly, when protective clothing is worn by workers, the relative penetration of the pesticide and tracer needs to be characterized. All of these limitations make fluorescent tracer methods technically challenging.

\section{Estimation of Exposure to Children in the Home}

Studies of children's exposure to pesticides in residential settings have adopted the general strategy employed in agricultural re-entry monitoring; exposure occurs 
post-application and is treated as the product of environmental concentrations and contact rate. Preliminary work in this area has focused on measurement of concentrations in air, on surfaces and in house dust (Hsu et al., 1990; Ross et al., 1991; Roberts et al., 1992; Simcox et al., 1995). Several recent studies have focused on children's exposures in agricultural communities (Loewenherz et al., 1997; Lu et al., 2000).

\section{BIOLOGICAL MONITORING}

Biological monitoring of pesticide exposures - the measurement of pesticides or their residues in biological fluids - has been conducted since the early 1950s, but has recently become the subject of renewed interest. Not all pesticides are amenable to biological monitoring. Pesticides that are rapidly absorbed and are neither sequestered nor metabolized to a significant extent, are usually good candidates, as are those for which a quantitative relationship between exposure and urinary metabolites can be established. Minimally, 80-90\% of the applied dose should be excreted in the urine within $5 \mathrm{~d}$. It is difficult for investigators to maintain control over field volunteers for longer periods that this. Ideally, the pharmacokinetic model should demonstrate sufficient excretion in 1-3 d. Biological monitoring should not be considered if the pharmacokinetics in humans are not well characterized; reliance on animal data is insufficient. Biomarkers of effect, such as the measurement of enzyme activity, are not addressed here. Biomarkers of exposure will be the subject of this section, including monitoring of pesticide metabolites in urine and of parent compounds in saliva. Several reviews have been published on the general topic of biological monitoring of pesticides (Wang et al., 1989; He, 1993; Woollen, 1993; ICPS, 1996). Details for the conduction of a study that includes biological monitoring are contained in the 1987 USEPA Guideline for applicator exposure monitoring (USEPA, 1987).

\section{Urinary Metabolite Monitoring}

Measurement of pesticide metabolites in urine holds the potential for developing a more accurate estimate of internal dose, and is particularly useful when exposure is from multiple routes, oral, as well as respiratory and dermal, as is almost always the case for pesticide-exposed workers. If the total urinary output is collected, until either there are no detectable residues or background levels are reached (usually 48-96h), the levels can be used to estimate the internal dose. Studies carried out in animals and humans for several pesticides have shown a good correlation between the amount of pesticide applied to the skin and the urinary output (Franklin et al., 1983, 1986; Popendorf and Franklin, 1987). However, there are limitations to using this approach. The pharmacokinetics of the pesticide must be known in humans, while those pesticides that are highly volatile are extensively metabolized to numerous minor metabolites or sequestered and are 
unlikely to result in an accurate estimate of dose. A complete discussion of this approach is presented in Woollen (1993) and OECD (1997).

Urine sampling may be conducted on a 'spot' basis (e.g. end-of-shift or morning void), or as a complete $24 \mathrm{~h}$ sample. This latter sample, while more easily interpretable, is often difficult to obtain from workers. Sample collection is relatively simple and noninvasive, although issues of privacy and confidentiality need to be addressed. Laboratory analysis is generally complex, and therefore expensive. New techniques, such as enzyme-linked immunosorbent assays (ELISAs) show promise as simple and cost-effective analytical methods. Such methods, while useful to indicate exposure, are not suitable for quantifying exposure.

Urinary metabolite measurements from spot samples have sometimes been adjusted by urinary creatinine concentration to account for hydration effects. However, creatinine itself may exhibit substantial intra- and inter-individual variability (Alessio et al., 1985; Boeniger et al., 1993). Creatinine may be measured by using a colorimetric method known as the Jaffe Reaction (Boeniger et al., 1993), or a specific-gravity method (Alessio et al., 1985). Most clinical laboratories can perform these two analyses at relatively cow cost. Urine specimens, showing physiologically implausible low or high levels of creatinine or specific gravity, should be viewed as suspect and possibly disregarded in a field study.

\section{Salivary Monitoring}

Saliva has recently been explored as a practical medium for monitoring exposures to a few environmental chemicals, including pesticides (Nigg and Wade, 1992). Carbaryl concentrations in saliva were found to parallel those in plasma after gavage administration in rats, thus suggesting that saliva may be suitable for monitoring carbaryl exposure (Skalasky et al., 1979). Salivary concentration of ethion was measured among pesticide applicators (Nigg et al., 1993). Elevated salivary ethion levels were observed in applicators following ethion spraying as compared to controls, and urinary metabolites levels and salivary ethion levels were somewhat correlated $(r=0.55)$, hence leading the authors to conclude that saliva could be used to confirm ethion exposure.

More recently, the feasibility of saliva monitoring for the herbicide atrazine has been studied in a systematic manner by using an animal model (Lu et al., 1997a, 1997b). Salivary concentrations of atrazine were found not only highly correlated to plasma levels under varying conditions, but salivary levels represent the portion of atrazine (protein-unbound) in plasma with toxicological significance (Lu et al., 1998). This technique was used recently in a study of atrazine-exposed applicators, and levels measured in saliva corresponded well with pesticide-application activities (Denovan et al., 2000). Measurements of pesticides in saliva have great potential, due to both the convenience of sample 
collection and to the expected reliability of salivary concentration as an indicator of tissue availability.

\section{VALIDATION OF PASSIVE DOSIMETRY}

One way to determine the accuracy of passive dosimetry at estimating dose would be to compare estimates derived from dosimetry with those from biological monitoring. Regulatory agencies receive studies conducted using both techniques, and while the following studies were not designed to validate passive dosimetry, they do indicate relatively good concordance between the two techniques.

\section{ATRAZINE}

Several studies using either passive dosimetry or biological monitoring, or both methods, were submitted by the registrant to assess exposure to workers in the US corn belt. The details of these studies are found in the USEPA Revised Human Health Risk Assessment (USEPA, 2002) and the USEPA Re-registration Eligibility Document (USEPA, 2003) on atrazine.

In the USA, the principal use of atrazine is in agriculture, and the major exposed workers are handlers who mix, load and apply atrazine to row crops. The passive dosimetry studies reported atrazine residues in terms of the parent compound only. The biological monitoring studies measured chlorotiazenes metabolites. The atrazine absorbed dose was 'back-calculated' from the measured metabolites based on a human excretion study. The results of the studies are reported in Table 1.3 and demonstrate fairly close concordance between the two methodologies.

Table 1.3 Comparison of biomonitoring and passive dosimetry data from atrazine exposure studies using closed mixing/loading systems and closed cabs (USEPA, 2002, 2003)

\begin{tabular}{llccc}
\hline Exposure scenario & Crop type & Study type & $\begin{array}{c}\text { Internal dose } \\
(\mu \mathrm{g} / \mathrm{kg} \text { of a.i. } \\
\text { handled })^{a}\end{array}$ & $\begin{array}{c}\text { 90th } \\
\text { percentile }\end{array}$ \\
\hline Mixing/loading liquid & Corn, sorghum Passive dosimetry & 1.14 & 21.14 \\
& & Biomonitoring & 1.28 & 9.68 \\
$\begin{array}{l}\text { Applying liquids with } \\
\text { ground-boom }\end{array}$ & Corn, sorghum Passive dosimetry & 1.59 & 64.70 \\
$\begin{array}{l}\text { application } \\
\begin{array}{l}\text { Mixing/loading/applying } \\
\text { liquids with ground- } \\
\text { boom application }\end{array}\end{array}$ & Biomonitoring & 1.34 & 15.20 \\
\hline
\end{tabular}

${ }^{a}$ a.i., active ingredient; geometric mean values.

${ }^{b}$ Passive dosimetry results are corrected for $6 \%$ dermal penetration based on a study in humans. 
The USEPA concluded that the unit exposures from both the passive and biological monitoring studies were within an order of magnitude of the values in the Pesticide Handler Exposure Database (PHED, 1992).

An additional biomonitoring study with greater than 100 replicates was not used in the risk assessment by USEPA due to the inability to relate results to the quantity of atrazine handled. The atrazine Reregistration Eligibility Document (RED) (USEPA, 2002) reports, however, that from this additional study, the range of daily dose per 'typical' agricultural handler of atrazine in various formulations using a variety of personal protective equipment and clothing and application equipment, confirmed the results of the concurrent biomonitoring and passive dosimetry results.

\section{CHLORPYRIFOS}

The USEPA reviewed a number of registrant-submitted studies to assess exposure to handlers applying chlorpyrifos in agricultural and residential settings (USEPA, 2001). The biomonitoring studies measured urinary concentrations of the primary chlorpyrifos metabolite and 'back-calculated' these to the absorbed dose of the parent. The passive dosimetry study results were corrected for $3 \%$ dermal absorption from a human dosing study (Nolan et al., 1984). The results of the studies are reported in Table 1.4 and demonstrate fairly close concordance between the two methodologies.

Another study monitored exposure to fifteen homeowners during application of a 'ready-to-use' chlorpyrifos product. The total absorbed dose estimated from the passive dosimetry study ranged from 0.3 to $0.86 \mathrm{mg} / \mathrm{kg} / \mathrm{d}$, with a mean of $0.25 \pm 0.25 \mathrm{mg} / \mathrm{kg} / \mathrm{d}$. Internal dose measured from the biological monitoring study ranged from 0 to $1.9 \mathrm{mg} / \mathrm{kg} / \mathrm{d}$, with an arithmetic mean of $0.49 \pm$ $0.59 \mathrm{mg} / \mathrm{kg} / \mathrm{d}$ and a geometric mean of $0.24 \mathrm{mg} / \mathrm{kg} / \mathrm{d}$, indicating relatively good agreement with the passive dosimetry results. It was postulated that ingestion of residues from the hands may have contributed to the higher biomonitoring results.

Another study monitored exposure to five workers using both passive dosimetry and biomonitoring during the application of chlorpyrifos as a termiticide. The mean absorbed chlorpyrifos dose of $4.27 \mathrm{mg} / \mathrm{kg} / \mathrm{d}$ from the biomonitoring study was comparable to that measured in the passive dosimetry study $(3.24 \mathrm{mg} / \mathrm{kg} / \mathrm{d})$.

In a third concurrent biomonitoring and passive dosimetry study, fifteen lawn care operators were evaluated. The geometric mean of the internal dose, based on biomonitoring was $0.4 \mathrm{mg} / \mathrm{kg} / \mathrm{d}$, and $0.079 \mathrm{mg} / \mathrm{kg} / \mathrm{d}$, based on comparable passive dosimetry.

\section{USE OF PHARMACOKINETIC DATA}

First, as made evident in the earlier discussion of personal monitoring methods, an accurate assessment of dermal contact exposure is technically challenging. Even whole-body garments worn close to the skin do not provide a complete assessment, as they miss such crucial areas as the neck, face, head and hands. 
Table 1.4 Comparison of concurrent biomonitoring and passive dosimetry data ${ }^{a}$ from chlorpyrifos exposure studies (USEPA, 2001)

Application method

Internal dose

$(\mu \mathrm{g} / \mathrm{kg}$ of a.i.

handled $)^{b}$

\begin{tabular}{|c|c|}
\hline \multicolumn{2}{|c|}{$\begin{array}{l}\text { Mixer/loader/applicator using high-pressure hand wand } \\
\text { (greenhouse ornamentals); 'Empire 20' formulation }\end{array}$} \\
\hline Biomonitoring & $1.15 \pm 1.13(n=13)$ \\
\hline Passive dosimetry & $3.85 \pm 7.7 \quad(n=13)$ \\
\hline \multicolumn{2}{|c|}{ Mixer/loader of the ' $50 \mathrm{~W}$ ' formulation (ground application to low crops) } \\
\hline Biomonitoring & $11.7 \pm 6.9(n=6)$ \\
\hline Passive dosimetry & $32.5 \pm 24.2(n=6)$ \\
\hline \multicolumn{2}{|c|}{ Mixer/loader of the ' $4 E$ ' formulation } \\
\hline Biomonitoring & $7.8 \pm 10(n=3)$ \\
\hline Passive dosimetry & $9.6 \pm 16(n=3)$ \\
\hline \multicolumn{2}{|c|}{ Applicator - Ground boom open cab ('4E' formulation) } \\
\hline Biomonitoring & $2.1 \pm 1.5(n=9)$ \\
\hline Passive dosimetry & $2.0 \pm 1.4(n=9)$ \\
\hline \multicolumn{2}{|c|}{ Mixer/loader - open mixing/loading ( $4 E$ ' formulation) } \\
\hline Biomonitoring & $10 \pm 21(n=15)$ \\
\hline Passive dosimetry & $6.2 \pm 6.2(n=15)$ \\
\hline \multicolumn{2}{|c|}{ Applicator air blast - open cab (' $4 E$ ' formulation) } \\
\hline Biomonitoring & $13 \pm 24(n=15)$ \\
\hline Passive dosimetry & $5.9 \pm 6.0(n=15)$ \\
\hline \multicolumn{2}{|c|}{ Mixer/loader/applicator ( $15 \%$ granular) } \\
\hline Biomonitoring & $0.73 \pm 0.33(n=12)$ \\
\hline Passive dosimetry & $0.3 \pm 0.36(n=16)$ \\
\hline \multicolumn{2}{|c|}{ Aerial mixer/loader of the ' $4 E$ ' formulation } \\
\hline Biomonitoring & $3.9+8.5(n=13)$ \\
\hline Passive dosimetry & $1.1+0.60(n=15)$ \\
\hline
\end{tabular}

${ }^{a}$ Passive dosimetry results $-3 \%$ dermal and $100 \%$ inhalation oral equivalent.

${ }^{b}$ a.i., active ingredient; mean \pm standard deviation (std); $n$, number of handlers/workers.

Secondly, estimates of dermal absorption are generally based on simple models, with data from animal studies. These models frequently do not account for the time-dependent nature of absorption and can produce significant inaccuracies in dose estimates (Kissel and Fenske, 2000). In particular, existing models do not account for skin uptake following the workshift. Such uptake will occur until an effective washing event occurs. For many workers, this may occur many hours after the end of work (e.g. bath or shower at bedtime or the following morning). Biological monitoring can, in theory, provide a fully integrated estimate of dose, but the pharmacokinetic database required for proper interpretation is substantial (Woolen, 1993). 


\section{EXPOSURE MITIGATION MEASURES}

Control or mitigation strategies for occupational exposures are normally expressed as a hierarchy, with engineering controls considered to be the first choice, administrative controls the second choice, and personal protection a choice of last resort. This approach has a sound basis in industrial hygiene practice and is outlined explicitly in the US Occupational Safety and Health Act of 1970. For pesticide handlers, however, this approach has not been adopted routinely. Rather, regulatory agencies worldwide have relied heavily on chemical protective clothing to mitigate exposures, and have made the use of such clothing a legal requirement for many compounds (USEPA, 1992; Easter and Nigg, 1992). While this is a sensible interim strategy, it should not be considered an adequate long-term control strategy for worker protection. Further efforts are needed to improve equipment design, application procedures and pesticide formulations to reduce exposures. Additionally, substitution of less hazardous compounds for pest control is the most certain means of preventing health risks for this population.

\section{EXPOSURE STUDIES SUPPORTING REGISTRATION DECISIONS}

Most regulatory agencies require worker exposure studies to be submitted by the registrant in support of registration. These studies are conducted using standardized protocols written up in guidance documents. In the United States, for example, the USEPA first produced guidelines for applicator exposure monitoring in 1987 (USEPA, 1987). More recently, agencies in North America and Europe have worked together to produce a harmonized guidance document in this area (Curry et al., 1995; OECD, 1997).

In many countries, such studies are to be conducted under standard procedures. For example, in the United States, studies are conducted under the Federal Insecticide, Fungicide and Rodenticide Act (FIFRA) Good Laboratory Practice (GLP) Standards (USEPA, 1989). These standards include well-defined quality assurance and chain-of-custody requirements. Comprehensive information regarding the implementation of GLP to pesticide handler field studies may be found in the work edited by Garner et al. (1992). Hawkins et al. (1992) have proposed a rationale and framework for the conducting of exposure assessments in support of risk management decisions, and outlined eight 'good exposure assessment practices' (GEAPs), essentially an extension of Good Laboratory Practices (GLPs) to field studies.

\section{STUDY DESIGN FACTORS AFFECTING EXPOSURE VARIABILITY}

All measurements of exposure will exhibit variability due to imprecision in sampling techniques or analytical procedures, and more importantly, due to the exposure conditions and the natural behaviour of the subject of study. If 
variability is random, then the central tendency of the exposure distribution will represent true exposure, and the variance will provide an estimate of the certainty of the exposure value. If, however, some characteristic of the procedure causes measured exposure values to be skewed systematically, then the true value will not be accurately reflected in the central tendency of the data. Such an effect is referred to as bias in epidemiology and occupational hygiene (Checkoway et al., 1989).

Pesticide exposure assessment studies conducted under current regulatory guidelines employ a sampling strategy in which a group of workers are recruited for the study and asked to conduct a single episode of pesticide handling, with the requirement that they apply the pesticide according to label directions. It is understood that this approach may reduce the exposure variability that might be seen in an uncontrolled situation. However, in most countries, it is illegal to apply pesticides in a manner that is inconsistent with the instructions on the label. Therefore, it would be inappropriate to require the registrant to conduct studies that did not adhere to label instructions.

\section{SPECIFIC REQUIREMENTS FOR GUIDELINE STUDIES}

\section{Label Compliance}

These requirements ensure that behaviours prohibited by the label will not occur, with a likely reduction in exposure values and their variability from those seen in an operational study. In particular, new chemical protective clothing is provided and workers are monitored to ensure adherence to its proper use. Field observations of current practice among pesticide handlers do not support these requirements as normal practices. In fact, dermal exposure is believed to result from inconsistent use, contamination and deterioration of chemical protective clothing. Similarly, guideline studies require that the spray application equipment be checked by experienced personnel for correct operation and application rate before the start of work. These actions are likely to eliminate or greatly reduce the incidence of accidents, mechanical repairs, and inadvertent overapplications due to miscalibration, resulting in reduced exposures when compared to normal agricultural practices.

\section{Sample Size}

Current guidance documents indicate that sample size should be based on the quality and nature of toxicological information, as well as on practical concerns related to the manageability of the field study; 10 to 15 measurements are recommended as a general guide. Teschke et al. (1994) have argued that a random sample of 10 is sufficient to calculate a mean exposure value, but that the variance derived from such a sample cannot be considered reliable. They concluded that for sample sizes less than 30 , a conservative estimate of the variance should be employed in determining percentile distributions from exposure data. 
There has been significant effort directed towards developing and using probabilistic techniques rather than the deterministic techniques for estimating exposure. The advantage of probabilistic methods is that they allow the full range of the exposure distribution to be characterized and used in the risk assessment. These techniques will help overcome the issues noted above but will require a fairly substantial database to accurately define the worker exposure distribution. A project has been initiated by the International Life Sciences Institute (ILSI) to develop guidelines on the use of probabilistic methods for pesticide worker exposure. A more detailed discussion of probabilistic methods is given in Chapter 8.

\section{Observational Bias}

Guideline studies normally last for one day. However, a worker's initial involvement in a study is a time when he or she is acutely aware that performance is under scrutiny. Thus, behaviour on the first day of the study is not likely to be typical. It has been a general observation in occupational hygiene that significant behavioural changes can occur among subjects on subsequent study days, with differences evident in their exposure values (i.e. exposure tends to increase). No current or proposed guidelines have addressed this issue, although it is common practice in many other human population studies to design procedures for controlling this effect.

\section{Motivational Bias}

What leads some workers to join pesticide exposure assessment studies when others do not? Since current human subjects guidelines require that participation in such studies must be voluntary, self-selection is a primary factor defining study populations. Several concerns can be raised here. First, financial incentives may be required to induce participation; yet workers who are paid for their participation may feel the need to perform well (i.e. to conduct applications in a careful manner). Secondly, those workers who routinely practice good health and safety may be much more willing to participate than those who feel that their normal behaviour will be viewed critically. Thirdly, in some cases a product undergoing registration review is perceived as highly beneficial among users. If so, they may develop 'loyalty' to the product, and be inclined to do the best they can to see that it garners approval.

Regulatory agencies are cognizant of uncertainties in estimating exposure due to worker motivational and observational biases, as well as the possibility that workers may not strictly adhere to the label directions when they are applying pesticides. As a result, regulators apply safety (uncertainty) factors and use conservative approaches to exposure assessment. For example, both the USEPA and Pest Management Regulatory Agency (PMRA) normalize exposure study data to the maximum application rate and use high end values for the amount of active ingredient used and for 
the number of hectares treated to avoid underestimating worker exposure. These inherent conservatisms are discussed in the introductory chapter.

Teschke et al. (1994) have examined the available strategies for assessing fungicide exposure in the lumber industry and concluded that representative sampling in an operational setting would provide the most accurate assessment of current exposures, in contrast to following a guideline study approach. The rationale for this conclusion was threefold: (1) such studies were unlikely to represent the full range of conditions that influence exposure, (2) this approach did not allow enumeration of the exposed population, and (3) small numbers of measurements collected under the guideline study were likely to introduce bias into the exposure assessment. It is recognized that actual operational use studies cannot be carried out for pesticides that are not yet registered or when for economic reasons it is not possible to enumerate the total exposed population.

\section{RECOMMENDATIONS FOR IMPROVEMENTS IN THE DESIGN OF GUIDELINE STUDIES}

\section{Population Selection}

Study participants should have substantial experience with the activity under study, and they should use their own equipment on their own property. It is also important that a single individual should not be used repeatedly as a subject. The practice of using one individual to produce a large number of 'replicates', tolerated under the EPA guidelines, clearly has the effect of artificially reducing between-worker variability in the exposure data. Most workplace exposure studies indicate that between-worker variability is greater than within-worker variability (Hawkins et al., 1991; Rappaport, 1991). Regulatory agencies recognize that repeated use of one worker is not ideal and typical practice is to require as many individual workers as possible to be monitored. The OECD guidelines (OECD, 1997) recommend a minimum of ten workers.

\section{Sampling Location}

Current guidance documents provide little detail on proper sampling locations. They do, however, indicate that sampling locations must be representative of where the product is to be used. Multiple sites are recommended, but decisions regarding specific locations are left to study investigators. Regulatory agencies typically require approval of study protocols and look for a science-based rationale for site selection. It would be more transparent to outsiders if there were detailed published criteria for selection of sites to ensure that they were representative of sites of concern.

\section{Sampling Season}

Relatively little guidance is provided regarding when to sample. One notable effect of season is the proper use of protective clothing. In many parts of the 
United States, for example, compliance with label requirements may occur in the spring, fall or winter, but not during the hotter months of summer. The effect of season on exposure has been documented in the timber mill industry, and it has been recommended that studies incorporate a seasonal component into their designs (Teschke et al., 1994).

\section{Duration of Measurements}

Full work shift samples should be collected whenever possible. Many exposure studies that are included in generic databases were of relatively short duration. For example, the USEPA (1987) guidelines require only that exterior sampling material have measurable levels of residues, resulting in some cases in samples of 10-20 min in duration. More recent guidelines stress the need for longer sampling periods (Chester, 1995; OECD, 1997).

\section{Post-Registration Studies}

Pesticide exposure assessment should not end with registration. Once a compound has come into general use, effective product stewardship should include periodic sampling of the exposed population and review of these data by regulatory agencies. Given the wide variety of equipment, application procedures and work practices, it is essential to determine whether in fact the exposure estimates derived from a combination of database information, assumptions, standard factors and controlled exposure trials reflect true exposure distributions in the exposed populations. Risk management decisions based on risk assessments, margins of uncertainty and feasibility considerations represent predictions that adverse health effects will not occur in the exposed population. Follow-up studies would ensure that these predictions were indeed accurate, and would provide a scientific foundation for altering regulations and conducting epidemiological research. The key design components of such post-registration studies would include the following: enumeration of the exposed population, stratification by worker group, random sampling within each strata, and calculation of the mean and variance of exposure within each group such that exposure distribution percentiles can be determined. If sample sizes are small in such studies, it would be necessary to employ conservative estimates of the variance.

\section{CONCLUSIONS AND RECOMMENDATIONS}

The field of pesticide exposure assessment is complex and challenging. Exposures occur through multiple routes and are highly variable. Risks associated with pesticide handling differ substantially for the different activities and from those experienced by agricultural re-entry workers. Different assessment and control strategies are needed for each population. Families of pesticide handlers can be 
exposed to pesticides and consideration of their children as a vulnerable subpopulation will likely lead to changes in the agricultural workplace that will reduce exposures for workers and families alike. Professional training in the fields of occupational hygiene and exposure assessment is needed to enhance the scientific capabilities of researchers and public health officials responsible for evaluating and controlling pesticide exposures.

\section{ACKNOWLEDGEMENTS}

This work was supported in part by the National Institute for Occupational Safety and Health (Pacific Northwest Agricultural Safety and Health Center, Co-operative Agreement No. U07/CCU012926).

\section{REFERENCES}

Alavanja, M.C.R., D.P. Sandler, S.B. McMaster, S.H. Zahm, C.J. McDonnell, C.F. Lynch, M. Pennybacker, N. Rothman, M. Dosemeci, A.E. Bond and A. Blair (1996). The Agricultural Health Study, Environ. Health Perspect., 104, 362-369.

Alessio, L., A. Berlin, A. Dell'Orto, F. Toffoletto and I. Ghezzi (1985). Reliability of Urinary Creatinine as a Parameter Used to Adjust Values of Urinary Biological Indicators, Int. Arch. Occup. Environ. Health, 55, 99-106.

Arbuckle, T.E., D.A. Savitz, L.S. Mery and K.M. Curtis (1999). Exposure to phenoxy herbicides and the risk of spontaneous abortion, Epidemiology, 10, 752-760.

Archibald, B.A., K.K. Solomon, G.R. Stephenson (1995). Estimation of Pesticide Exposure to Greenhouse Applicators Using Video Imaging and Other Assessment Techniques, Am. Ind. Hyg. Assoc. J., 56, 226-235.

Batchelor, G.S. and K.C. Walker (1954). Health Hazards Involved in the Use of Parathion in Fruit Orchards in North Central Washington, AMA Arch. Ind. Hyg., 10, $522-529$.

Bierman, E.P.B., D.H. Brouwer and J.J. van Hemmen (1998). Implementation and evaluation of the fluorescent tracer technique in greenhouse exposure studies, Ann. Occup. Hyg., 42, 467-475.

Boeniger, M.F., L.K. Lowry and J. Rosenberg (1993). Interpretation of Urine Results Used to Assess Chemical Exposure with Emphasis of Creatinine Adjustments: A Review, Am. Ind. Hyg. Assoc. J., 54, 615-627.

Brouwer, R., H. Marquart, G. De Mik and J.J. Van Hemmen (1992). Risk Assessment of Dermal Exposure of Greenhouse Workers to Pesticides After Re-Entry, Arch. Environ. Contam. Toxicol., 23, 273-280.

Buringh, E. and R. Lanting (1991). Exposure variability in the workplace: its implications for the assessment of compliance, Am. Ind. Hyg. Assoc. J., 52, 6-13.

Cannon, S.B., J.M. Veazey, R.S. Jackson, V.W. Burse, C. Hayes, W.E. Straub, P.F. Landrigan and J.A. Liddle (1978). Epidemic Kepone Poisoning in Chemical Workers, Am. J. Epidem., 107, 529-537.

Checkoway, H., N.E. Pearce and D.J. Crawford-Brown (1989). Research Methods in Occupational Epidemiology, Oxford University Press, New York.

Chester, G. (1995). Revised guidance document for the conduct of field studies of exposure to pesticides in use, in Methods of Pesticide Exposure Assessment, P.B. Curry, S. Iyengar, P.A. Maloney and M. Maroni (Eds), Plenum Press, London, pp. 179-215. 
Chester, G., N.N. Sabapathy and B.H. Woollen (1992). Exposure and Health Assessment During Application of Lambda-Cyhalothrin for Malaria Vector Control in Pakistan, Bull. World Health Org., 70, 615-619.

Chiao-Cheng, J.H., B.M. Reagan, R.R. Bresee, C.E. Meloan and A.M. Kadoum (1989). Carbamate Insecticide Removal in Laundering from Cotton and Polyester Fabrics, Arch. Environ. Contam. Toxicol., 17, 87-94.

Clifford, N.J. and A.S. Nies (1989). Organophosphate Poisoning from Wearing a Laundered Uniform Previously Contaminated with Parathion, JAMA, 262, 3035-3036.

Corn, M. and N.A. Esmen (1979). Workplace exposure zones for classification of employee exposures to physical and chemical agents, Am. Ind. Hyg. Assoc. J., 40, 47-57.

Curry, P.B., S. Ivengar, P.A. Maloney and M. Maroni (Eds) (1995). Methods of Pesticide Exposure Assessment, NATO Committee on the Challenges of Modern Society, Plenum Press, New York.

Davis, J.E. (1980). Minimizing Occupational Exposure to Pesticides: Personal Monitoring, Residue Rev., 75, 33-50.

Davis, J.E., E.R. Stevens and D.C. Staff (1983). Potential Exposure of Apple Thinners to Azinphosmethyl and Comparison of Two Methods for Assessment of Hand Exposure, Bull. Environ. Contam. Toxicol., 31, 631-638.

Denovan, L.A., C. Lu, C.J. Hines and R.A. Fenske (2000). Saliva biomonitoring of atrazine exposure among herbicide applicators, Int. Arch. Occup. Environ. Health, 73, 457-462.

Durham, W.F. and H.R. Wolfe (1962). Measurement of the Exposure of Workers to Pesticides, Bull. WHO, 26, 75-91.

Easter, E.P. and H.N. Nigg (1992). Pesticide Protective Clothing, Rev. Environ. Contam. Toxicol., 129, 1-16.

Fenske, R.A. (1988). Visual Scoring System for Fluorescent Tracer Evaluation of Dermal Exposure to Pesticides, Bull. Environ. Contam. Toxicol., 41, 727-736.

Fenske, R.A. (1990). Nonuniform Dermal Deposition Patterns During Occupational Exposure to Pesticides, Arch. Environ. Contam. Toxicol., 19, 332-227.

Fenske, R.A. (1993a). Dermal Exposure Assessment Technique, Ann. Occup. Hyg., 37, 687-706.

Fenske, R.A. (1993b). Fluorescent Tracer Evaluation of Protective Clothing Performance. Final Report, US Environmental Protection Agency, Risk Reduction Engineering Laboratory, Office of Research and Development, Cincinnati, OH, USA.

Fenske, R.A. and S.G. Birnbaum (1997). Second Generation Video Imaging Technique for Assessing Dermal Exposure (VITAE System), Am. Ind. Hyg. Assoc. J., 58, 636-645.

Fenske, R.A. and C. Lu (1994). Determination of Handwash Removal Efficiency: Incomplete Removal of the Pesticide, Chlorpyrifos, from Skin by Standard Handwash Techniques, Am. Ind. Hyg. Assoc. J., 55, 425-432.

Fenske, R.A., J.T. Leffingwell and R.C. Spear (1985). Evaluation of Fluorescent Tracer Methodology for Dermal Exposure Assessment, in Dermal Exposure Related To Pesticide Use, R.C. Honeycutt, G. Zweig and N.N. Ragsdale (Eds), ACS Symposium Series 273, American Chemical Society, Washington, DC, USA, pp. 377-393.

Fenske, R.A., S.M. Wong, J.T. Leffingwell and R.C. Spear (1986). A Video Imaging Technique for Assessing Dermal Exposure - II. Fluorescent Tracer Testing, Am. Ind. Hyg. Assoc. J., 47, 771-775.

Fenske, R.A., S.G. Birnbaum, M.M. Methner and R. Soto (1989). Methods for Assessing Fieldworker Hand Exposure to Pesticides During Peach Harvesting, Bull. Environ. Contam. Toxicol., 43, 805-815.

Fenske, R.A., A.M. Blacker, S.J. Hamburger and G.S. Simon (1990). Worker Exposure and Protective Clothing Performance during Manual Seed Treatment with Lindane, Arch. Environ. Contam. Toxicol., 19, 190-196. 
Fenske, R.A., N.J. Simcox, J.E. Camp and C.J. Hines (1999). Comparison of three methods for assessment of hand exposure to azinphosmethyl (guthion) during apple thinning, Appl. Occup. Environ. Hyg., 14, 618-623.

Franklin, C.A., R.A. Fenske, R. Greenhalgh, L. Mathieu, H.V. Denley, J.T. Leffingwell and R.C. Spear (1981). Correlation of urinary pesticide metabolite excretion with estimated dermal contact in the course of occupational exposure to Guthion, J. Toxicol. Environ. Health, 7, 715-731.

Franklin, C.A., R. Greenhalgh and H.I. Maibach (1983). Correlation of urinary dialkyl phosphate metabolite levels with dermal exposure to azinphos-methyl, in Human Welfare and the Environment, Vol. 3, J. Miyamoto and P.C. Kearney (Eds), Pergamon Press, Oxford, UK, pp. 221-226.

Franklin, C.A., N.I. Muir and R.P. Moody (1986). The use of biological monitoring in the estimation of exposure during the application of pesticides, Toxicol. Lett., 33, 127-136.

Garner, W.Y., M.S. Barge and J.P. Ussary (Eds) (1992). Good Laboratory Practice Standards: Applications for Field and Laboratory Studies, American Chemical Society, Washington, DC, USA.

Garry, V.F., D. Schreinemachers, M.E. Harkins and J. Griffith (1996). Pesticide Appliers, Biocides and Birth Defects in Rural Minnesota, Environ. Health Perspect., 104, 394-399.

Geno, P.W., D.E. Camann, J.H. Harding, K. Villalobos and R.G. Lewis (1996). Handwipe sampling and analysis procedure for the measurement of dermal contact with pesticides, Arch. Environ. Contam. Toxicol., 30, 132-138.

Gold, R.E., J.R.C. Leavitt, T. Holsclaw and D. Tupy (1982). Exposure of Urban Applicators to Carbaryl, Arch. Environ. Contam. Toxicol., 11, 63-67.

Hawkins, N.C., S.K. Norwood and J.C. Rock (1991). A Strategy for Occupational Exposure Assessment, American Industrial Hygiene Association, Akron, OH, USA.

Hawkins, N.C., M.A. Jayjock and J. Lynch (1992). A rationale and framework for establishing the quality of human exposure assessments, Am. Ind. Hyg. Assoc. J., 53, 34-41.

He, F. (1993). Biological Monitoring of Occupational Pesticides Exposure, Int. Arch. Occup. Environ. Health, 65, S68-S76.

Hsu, J.P., D. Camann, H. Schattenberg, H. Wheeler, K. Villalobos, M. Kyle and S. Quarderer (1990). New Dermal Exposing Sampling Technique, in Measurement of Toxic and Related Air Pollutants, Air and Waste Management Association Publications, Pittsburgh, PA, USA, pp. 489-497.

ICPS (1996). Biological Monitoring of Human Exposure to Pesticides, International Centre for Pesticide Safety, Milan, Italy (draft).

Keeble, V.B., R.R. Dupont, W.J. Doucette and M. Norton (1988). Guthion Penetration of Clothing Materials during Mixing and Spraying in Orchards, in Performance Of Protective Clothing: Second Symposium, S.Z. Mansdorf, R. Sagar and A.P. Nielson (Eds), American Society For The Testing Of Materials, Philadelphia, PA, USA, Std 989, pp. 573-583.

Kissel, J.C. and R.A. Fenske (2000). Improved estimation of dermal pesticide dose to agricultural workers upon re-entry, Appl. Occup. Environ. Hyg., 15, $1-7$.

Kristensen, P., A. Andersen, L.M. Irgens, A.S. Bye and L. Sundheim (1996). Cancer in Offspring of Parents Engaged in Agricultural Activities in Norway: Incidence and Risk Factors in the Farm Environment, Int. J. Cancer, 65, 39-50.

Kromhout, H., E. Symanski and S.M. Rappaport (1993). A comprehensive evaluation of within and between worker components of occupational exposure to chemical agents, Ann. Occup. Hyg., 37, 253-270.

Kross, B.C., H.F. Nicholson and L.K. Ogilvie (1996). Methods Development Study for Measuring Pesticide Exposure to Golf Course Workers using Video Imaging Techniques, Appl. Occup. Environ. Hyg., 11, 1346-1350. 
Loewenherz, C., R.A. Fenske, N.J. Simcox, G. Bellamy and D. Kalman (1997). Biological Monitoring of Organophosphorous Pesticide Exposure among Children of Agricultural Workers, Environ. Health Perspec., 105, 1344-1353.

Lu, C., L.C. Anderson and R.A. Fenske (1997a). Determination of Atrazine Levels in Whole Saliva and Plasma in Rats: Potential of Salivary Monitoring for Occupational Exposure, J. Toxicol. Environ. Health, 50, 101-111.

Lu, C., L.C. Anderson, M.S. Morgan and R.A. Fenske (1997b). Correspondence of Salivary and Plasma Concentrations of Atrazine in Rats under Variable Salivary Flow Rate and Plasma Concentration, J. Toxicol. Environ. Health, 52, 317-329.

Lu, C., L.C. Anderson, M.S. Morgan and R.A. Fenske (1998). Salivary Concentration of Atrazine can be Used to Determine Free Atrazine Plasma Levels in Rats, J. Toxicol. Environ. Health, 53, 283-292.

Lu, C., R.A. Fenske, N.J. Simcox and D. Kalman (2000). Pesticide exposure of children in an agricultural community: evidence of household proximity to farmland and take home exposure pathways, Environ. Res., 84, 290-302.

Machado, J., G. Neto, T. Matuo and Y.K. Matuo (1992). Dermal Exposure of Pesticide Applicators in Staked Tomato (Lycopersicon Esculentum Mill) Crops: Efficiency of a Safety Measure in the Application Equipment, Bull. Environ. Contam. Toxicol., 48, 529-534.

Methner, M.M. and R.A. Fenske (1994a). Pesticide Exposure During Greenhouse Applications, Part I. Dermal Exposure Reduction Due to Directional Ventilation and Worker Training, Appl. Occup. Environ. Hyg., 9, 560-566.

Methner, M.M. and R.A. Fenske (1994b). Pesticide Exposure During Greenhouse Applications, Part II. Chemical Permeation Through Protective Clothing in Contact With Treated Foliage, Appl. Occup. Environ. Hyg., 9, 567-574.

NAS (1983). Risk Assessment in the Federal Government: Managing the Process, National Academy of Sciences, National Academy Press, Washington, DC, USA.

Nicas, M., B.P. Simmons and R.C. Spear (1991). Environmental versus analytical variability in exposure measurements, Am. Ind. Hyg. Assoc. J., 52, 553-557.

Nigg, H.N. and S.E. Wade (1992). Saliva as a Monitoring Medium for Chemicals, Rev. Environ. Contam. Toxicol., 129, 95-119.

Nigg, H.N., H.H. Stamper and R.M. Queen (1986). Dicofol Exposure to Florida Citrus Applicators: Effects of Protective Clothing, Arch. Environ. Contam. Toxicol., 15, $121-134$.

Nigg, H.N., R.C. Beier, O. Carter, C. Chaisson, C. Franklin, T. Lavy, R.G. Lewis, P. Lombardo, J.F. McCarthy, K.T. Maddy, M. Moses, D. Norris, C. Peck, K. Skinner and R.G. Tardiff (1990). Exposure to pesticides, in The Effect of Pesticides on Human Health, S.R. Baker and C.F. Wilkinson (Eds), Princeton Scientific Publishing, Princeton, NJ, USA, Ch. 2, pp. 35-130.

Nigg, H.N., J.H. Stamper, E. Easter and J.O. Dejong (1992). Field Evaluation of Coverall Fabrics: Heat Stress and Pesticide Penetration, Arch. Environ. Contam. Toxicol., 23, 281-288.

Nigg, H.N., J.H. Stamper and L.L. Mallory (1993). Quantification of Human Exposure to Ethion using Saliva, Chemosphere, 26, 897-906.

NIOSH (1995). Report to Congress on Worker's Home Contamination Study Conducted Under the Workers' Family Protection Act, US Department of Health and Human Services, National Institute for Occupational Safety and Health, Cincinnati, OH, USA (website: http://www.cdc.gov/niosh/publiste.html).

Nolan, R.J., D.L. Rick, N.L. Freshour and J.H. Saunders (1984). Chlorpyrifos: pharmacokinetics in human volunteers, Toxicol. Appl. Pharmacol., 73, 8-15.

OECD (1997). Guidance Document for the Conduct of Occupational Exposure to Pesticides during Agricultural Application, OECD Environmental Health and Safety Publications, 
Series on Testing and Assessment, No. 9, OCDE/GD(97)148, Paris, France (website: http://www.olis.oecd.org/olis/1977doc.nsf - search for OCDE/GD(97)148).

PHED (1992). Notice of Availability of the Pesticide Handlers Exposure Database Version 1.1 through VERSAR, Inc., Arlington, VA, USA, Federal Register, 57(107), 23403-23404, June 3, Washington, DC, USA.

Popendorf, W. and C.A. Franklin (1987). Pesticide Exposure Assessment, in Pesticide Science and Biotechnology, R. Greenhalgh and T.P. Roberts (Eds), Blackwell Scientific Publishers, Oxford, UK, pp. 565-568.

Rappaport, S.M. (1991). Assessment of long-term exposures to toxic substances in air, Ann. Occup. Hyg., 35, 61-121.

Richter, E.D., M. Kowalski, A. Leventhal, F. Grauer, J. Marzouk, S. Brenner, I. Shkolnik, S. Lerman, H. Zahavi, A. Bashari, A. Peretz, H. Kaplanski, N. Gruener and P. Ben Ishai (1992). Illness and Excretion of Organophosphate Metabolites Four Months after Household Pest Extermination, Arch. Environ. Health, 47, 135-138.

Roberts, J.W., W.T. Budd, M.G. Ruby, D.E. Camann, R.C. Fortmann, R.G. Lewis, L.A. Wallace and T.M. Spittler (1992). Human Exposure to Pollutants in the Floor Dust of Homes and Offices, J. Expo. Anal. Environ. Epidem., 2, 127-146.

Roff, M.W. (1994). A Novel Lighting System for the Measurement of Dermal Exposure using a Fluorescent Dye and an Image Processor, Ann. Occup. Hyg., 38, 903-919.

Ross, J., H.R. Fong, T. Thongsinthusak, S. Margetich and R. Krieger (1991). Measuring Potential Dermal Transfer of Surface Pesticide Residue Generated from Indoor Fogger Use: Using the CDFA Roller Method, Interim Report II, Chemosphere, 22, 975-984.

Simcox, N.J., R.A. Fenske, S. Wolz, I. Lee and D. Kalman (1995). Organophosphate Pesticide Residues in Residential Housedust and Soil in the Tree Fruit Region of Washington State, Environ. Health Perspect., 103, 1126-1134.

Skalasky, H.L., R.W. Lane and J.F. Borzelleca (1979). Excretion of Carbaryl into Saliva of the Rat and its Effect on Cholinesterase, in Toxicology and Occupational Medicine, W.B.E. Reichmann (Ed.), Elsevier Science, Miami, FL, USA, pp. 22-25.

Teschke, K., S.A. Marion, A. Jin, R.A. Fenske and C. van Netten (1994). Strategies for determining occupational exposures in risk assessments: a review and a proposal for assessing fungicide exposures in the lumber industry, Am. Ind. Hyg. Assoc. J., 55, 443-449.

USEPA (1987). Pesticide Assessment Guidelines, Subdivision U, Applicator Exposure Monitoring, Report No. 540/9-87-127, Office of Prevention, Pesticides and Toxic Substances, Washington, DC, USA (website: http://www.epa.gov/pesticides).

USEPA (1989). Federal Insecticide, Fungicide and Rodenticide Act (FIFRA); Good Laboratory Practice Standards (Final Rule), Federal Register, 40(160), 34052-34074, August 17, Washington, DC, USA.

USEPA (1992). Worker Protection Standard (Final Rule), Federal Register, 57(163), 38102-38166, August 21, Washington, DC, USA.

USEPA (1998). Post Application Guidelines: Series 875 - Group B - Occupational and Residential Exposure Test Guidelines, Version 5.4, Office of Prevention, Pesticides and Toxic Substances, Washington, DC, USA (website: http://www.epa.gov/oscpmont/sap/ march/contents.htm).

USEPA (2001). Interim Reregistration Eligibility Document for Chlorpyrifos, Case No. (0100), Environmental Protection Agency, Washington, DC, USA.

USEPA (2002). Atrazine Revised Human Health Assessment for the Reregistration Eligibility Document (RED), Case No. (0062), Environmental Protection Agency, Washington, DC, USA.

USEPA (2003). Interim Reregistration Eligibility Document for Atrazine, Case No. (0062), Environmental Protection Agency, Washington, DC, USA.

van Hemmen, J.J. (1992). Agricultural Pesticide Exposure Data Bases for Risk Assessment, Rev. Environ. Contam. Toxicol., 126, 1-85. 
Wang, R.G., C.A. Franklin, R.C. Honeycutt and J.C. Reinert (Eds) (1989). Biological Monitoring for Pesticide Exposure, ACS Symposium Series 382, American Chemical Society, Washington, DC, USA.

Ware, G.W. (1994). The Pesticide Book, 4th Edn, Thomson Publications, Fresno, CA, USA.

WHO (1986). World Health Organization Field Surveys of Exposure to Pesticides Standards, Protocol Toxicol. Lett., 33, 223-235.

Wolfe, H.R. (1976). Field exposure to airborne pesticides, in Air Pollution from Pesticides and Agricultural Processes, R.E. Lee, Jr (Ed.), CRC Press, Cleveland, OH, USA, pp. $137-161$.

Woollen, B.H. (1993). Biological Monitoring for Pesticide Absorption, Am. Occup. Hyg., 37, 525-540. 
